\title{
Glyburide Attenuates B(a)p and LPS-Induced Inflammation-Related Lung Tumorigenesis in Mice
}

\section{Mengyuan Li}

Zhengzhou University

\section{Hong Liu}

Zhengzhou University First Affiliated Hospital

Hua Shao

Zhengzhou university

\section{Peng Zhang}

Henan Cancer Hospital

\section{Min Gao}

Zhengzhou University

\section{Li Huang}

Zhengzhou University

\section{Pingping Shang}

Zhengzhou Tobacco Research Institute

\section{Qiao Zhang}

Zhengzhou University

\section{Wei Wang}

Zhengzhou University school

\section{Jing Wang}

Zhengzhou University First Affiliated Hospital

Feifei Feng ( $\nabla$ feifeifeng@zzu.edu.cn )

Zhengzhou University https://orcid.org/0000-0001-5534-5928

\section{Research}

Keywords: Glyburide, Lung tumorigenesis, NLRP3; Benzo(a)pyrene, Lipopolysaccharide

Posted Date: July 30th, 2020

DOI: https://doi.org/10.21203/rs.3.rs-48981/v1

License: (c) (1) This work is licensed under a Creative Commons Attribution 4.0 International License. Read Full License 
Version of Record: A version of this preprint was published at Environmental Toxicology on May 26th, 2021. See the published version at https://doi.org/10.1002/tox.23293. 


\section{Abstract}

Background: Glyburide (Gly) serves as inhibitor of NLRP3 inflammasome, which is also one of the most common medication used in the treatment of type 2 diabetes. Although accumulating evidences suggest that Gly could affect cancer risk and tumor growth, the role of chronic Gly treatment in lung tumorigenesis remains unclear. In this study, we evaluated whether Gly inhibited the occurrence of lung cancer and explored the possible mechanisms in the non-diabetes mice model of inflammation-related lung cancer induced by benzo(a)pyrene [B(a)p] plus lipopolysaccharide (LPS).

Methods: The C57BL/6J mice exposed to B(a)p (1 mg/mouse, once a week for 4 times) and 3 weeks later instilled intratracheally with LPS $(2.5 \mu \mathrm{g} /$ mouse, once every three weeks for 5 times), and the Gly was administered by gavage (at a dose of $10 \mu \mathrm{l} / \mathrm{g}$ body weight) one week before the mice exposed to $\mathrm{B}(\mathrm{a}) \mathrm{p}$ until the animal model finished (the week of the first time of Gly treatment named Week 0). At week 34, we analyzed the incidence, number and histopathology of lung tumors, and detected the expression of NLRP3, IL-1 $\beta$ and Cleaved-IL-1 $\beta$ protein.

Results: Vehicles and tricaprylin+Gly could not induce lung tumorigenesis in the whole process. The incidence and the mean tumor count of mice in B(a)P/LPS+Gly group was decreased compared to those in $B(a) p$ plus LPS group respectively. Histopathological examination found that Gly-treatment alleviated inflammatory changes compared with mice exposed to B(a)p plus LPS and revealed a reduction of the number of pathological tumor nest in the B(a)P/LPS+Gly group compared to the $B(a) p$ plus LPS group. The expression of NLRP3, IL-1 $\beta$ and Cleaved-IL-1 $\beta$ protein was significantly increased in B(a)p plus LPS group compared to Vehicle control group, but decreased in B(a)P/LPS+Gly $(0.96 \mathrm{mg} / \mathrm{kg})$ group compared to $B(a) p$ plus LPS group.

Conclusions: Glyburide might inhibit NLRP3 inflammasome to attenuate B(a)p plus LPS-induced inflammation-related lung tumorigenesis in non-diabetes mice.

\section{Introduction}

International Agency for Research on Cancer reported that lung cancer is the primary factor of cancerrelated morbidity and death[1], the estimated new cases of lung cancer ranked second and the estimated deaths of lung cancer ranked first in United States, 2020[2]. A large of evidences have shown that occupational exposures are associated closely with lung cancer[3], and Polycyclic Aromatic Hydrocarbons serve as occupational exposures for people work in such occupational environments could increase the risk of lung cancer[4]. As an important and most investigated inflammatory regulator, NLRP3 inflammasome has been reported to play a critical role in tumorigenesis, and recently studies show that inflammasomes serve as a promising therapeutic target for the prevention and treatment of cancer $[5,6]$. In our previous study, we investigated the role of NLRP3 in mouse inflammation-related lung cancer initiation, and found that NLRP3 deletion inhibited lung cancer initiation induced by $\mathrm{B}(\mathrm{a}) \mathrm{p}$ or $\mathrm{B}(\mathrm{a}) \mathrm{p}$ plus 
LPS[7], we also found that NLRP3 inflammasome activation played an important role in B(a)p plus LPSinduced inflammation-related lung tumorigenesis in mice[8].

Glyburide, a NLRP3 inhibitor, plays an anti-inflammatory role to inhibit the NLRP3 inflammasome, decreases the production of proinflammatory cytokines, reduces the recruitment and migration of inflammatory cells, and production of nitricoxide[9]. In addition, glyburide is a second-generation oral antidiabetic drug known as sulphonylureas, which is one of insulin secretatogues widely used for noninsulin-dependent diabetes mellitus. Growing evidence demonstrated that glyburide played a critical role in antitumor effect, which basically by two kinds of mechanisms: a general inhibitor of the ABC protein super-family and an inhibitor of KATP channels[10]. There are conflicting results which were reported in clinical studies regarding the potential effect of sulfonylureas increasing or decreasing cancer risks, some studies showed that glyburide was associated with higher cancer risks and mortality[11-13], such as breast cancer[14], while according to the other studies revealed opposite findings that glyburide could reduce cancer risks[15], such as prostate cancer[16, 17]. Furthermore, in some early studies about cancer cells, it demonstrated that glyburide could inhibit progression in many cancers such as bladder carcinoma[18], prostate cancer[19], colon cancer[20], and liver cancer[21, 22].Moreover, few in vivo studies have discussed the involvement of glyburide in lung tumorigenesis, especially in the non-diabetes mice model. One research observed the impact of chronic glyburide treatment on breast carcinoma growth in prediabetic obese rats. It showed that glyburide treatment alleviated tumor growth by $27 \%$ in rats, and demonstrated tumor growth inhibition might be a more direct effect of glyburide[23]. Another research about the impact of glyburide on mammary cancer induced by $N$-Nitroso- $N$-Methylureain diabetes and non-diabetes rats indicating the antitumor action in vivo of glyburide in nondiabetic rats[24]. However, the involvement of glyburide in lung tumorigenesis remains unclear.

The objective of our study was to investigate whether glyburide inhibit the occurrence of lung cancer, so we established the non-diabetes mice model of inflammation-related lung cancer induced by $B(a) p$ plus LPS which have been reported in our previous study[7], and the glyburide treatment were administered from one week before the mice were intratracheal instillation with $B(a) p$. This study could provide an important guiding significance for the medication with lung cancer.

\section{Materials And Methods}

\section{Animals}

C57BL/6J mice (SPF degree, 6-8 week) were obtained from their heterozygous littermates in the college of Public Health of Zhengzhou University, Henan, China (temperature $22^{\circ} \mathrm{C}$, lights on 08:00-20:00), and were kept in stainless steel cages with water and food ad libitum. All studies were approved by the life Science Institutional Review Board of Zhengzhou University and performed strictly in accordance with the Guideline of Zhengzhou University for Animal Experiments.

\section{Inflammation-related lung tumorigenesis mouse models and glyburide treatment}


The inflammation-related lung tumorigenesis models in the mouse were induced by intratracheal instillation with B(a)p and LPS. Mice were divided into 6 groups randomly: Group 1: Vehicle control group ( $n=16)$, Group 2: B(a)p plus LPS group ( $n=30)$, Group 3: tricaprylin+Gly $(0.48 \mathrm{mg} / \mathrm{kg})$ group $(n=19)$, Group 4: $\mathrm{B}(\mathrm{a}) \mathrm{P} / \mathrm{LPS}+\mathrm{Gly}(0.48 \mathrm{mg} / \mathrm{kg})$ ( $n=31)$, Group 5: tricaprylin+Gly $(0.96 \mathrm{mg} / \mathrm{kg})$ group $(n=16)$ and Group 6: $\mathrm{B}(\mathrm{a}) \mathrm{P} / \mathrm{LPS}+\mathrm{Gly}(0.96 \mathrm{mg} / \mathrm{kg})(n=34)$. As shown in Fig.1, mice in groups $\mathrm{B}(\mathrm{a}) \mathrm{p}$ plus LPS, $B(a) P / L P S+G l y(0.48 \mathrm{mg} / \mathrm{kg})$ and $B(a) P / L P S+G l y(0.96 \mathrm{mg} / \mathrm{kg}$ ) were instilled intratracheally with $B(a) p$ (at a dose of $1 \mathrm{mg} / \mathrm{mouse}$ in $50 \mu$ tricaprylin) once a week for 4 times. 3 weeks later, these mice were instilled intratracheally with LPS (at a dose of $2.5 \mu \mathrm{g} /$ mouse in $50 \mu \mathrm{l}$ physiological saline solution) once every three weeks for 5 times, whereas mice in group Vehicle control, tricaprylin+Gly $(0.48 \mathrm{mg} / \mathrm{kg})$ and tricaprylin+Gly $(0.96 \mathrm{mg} / \mathrm{kg})$ were given $50 \mu$ tricaprylin in a similar manner. All instillations were administered under isoflurane (Sigma) anesthesia. To explore the potential of chronic Gly treatment as a preventive measure against tumorigenesis, mice in group tricaprylin+Gly $(0.48 \mathrm{mg} / \mathrm{kg})$, $\mathrm{B}(\mathrm{a}) \mathrm{P} / \mathrm{LPS}+\mathrm{Gly}(0.48 \mathrm{mg} / \mathrm{kg})$, tricaprylin+Gly $(0.96 \mathrm{mg} / \mathrm{kg}), \mathrm{B}(\mathrm{a}) \mathrm{P} / \mathrm{LPS}+\mathrm{Gly}(0.96 \mathrm{mg} / \mathrm{kg})$ were administered the Gly $(0.48 \mathrm{mg} / \mathrm{kg}$ or $0.96 \mathrm{mg} / \mathrm{kg}$, dissolved in $50 \mu$ lsaline) treatment (gavage, three times a week) from one week before the mice were instilled intratracheally with $B(a) p$ (the week of the first time of Gly treatment named Week 0 ) until the animal model finished. The Gly-treated mice were weighed and their fast blood glucose (FBG) were measured before the modeling process, and were also weighted and measured about once a month in subsequent studies. At week 34, the mice were anesthesia by penrobarbital sodium (1\%) and then sacrificed to harvest lungs to count visible tumors on the surface of the lung tissues. The left lobes of the lungs of all groups were used for histopathological studies which were fixed by $4 \%$ paraformaldehyde, then the right lobes of the lungs were preserved in $-80^{\circ} \mathrm{C}$ and used for subsequent studies.

\section{Lung coefficient}

At week 34, the lung tissues were removed from sacrificed mice, washed in physiological saline solution, sucked dry by filter paper, and then weighted with electronic balance. Lung coefficient could be one of the indicators of lung injury, which was expressed as the follow equation: Lung coefficient=lung weight/body weight.

\section{Lung pathological alterations}

The left lobes of the lungs were fixed overnight by $4 \%$ paraformaldehyde, embedded in paraffin, then cut into sections having a thickness of $5 \mu \mathrm{m}$. Eventually, the sections were observed by an electron microscope using haematoxylin and eosin(HE) staining. To evaluate the inflammation changes of lung tissues according to the literature published by Huang et al[25]. The pathological tumor nests were identified by two experienced pathologists in a blind manner and based on the previous papers published[26, 27].

\section{Immunohistochemistry}


The expression of NLRP3, IL-1 $\beta$, IL-18 protein in lung tissues were determined by immunohistochemistry (IHC). Lung tissue sections were blocked with goat serum for 30 mins at room temperature firstly and incubated with rabbit anti-mouse antibodies at a dilution of 1:100 including NLRP3 (Servicebio, Wuhan, China), IL-1 $\beta$ (Servicebio, Wuhan, China) and IL-18 (Servicebio, Wuhan, China) at $4^{\circ} \mathrm{C}$ overnight, followed by incubation with biotinylated goat anti-rabbit immunoglobulin (1:100 dilution) for 50 minutes at $37^{\circ} \mathrm{C}$. Positive IHC staining was reflected as brown staining and the AOD quantification was carried out using the Image-Pro Plus 6.0 software in the high-power vision fields (AOD = Integrated Optical Density [IOD] SUM/Area SUM).

\section{Western Blot}

Mice lung tissues were lysed using RIPA reagent (CWBio, Beijing, China) containing $100 \mu \mathrm{g} / \mathrm{mL}$ PMSF (CWBio, Beijing, China), protein concentration quantified using BCA Protein Assay Kit (CWbio, Beijing, China), protein samples were mixed with loading buffer and boiled for 5 minutes. Proteins were isolated by $12 \%$ or $15 \%$ SDS-PAGE and transferred onto Polyvinylidene Fluoride (PVDF) membranes. Membranes were blocked by $5 \%$ milk in TBST for 2 hours at room temperature, then incubated overnight at $4{ }^{\circ} \mathrm{C}$ with 1:1000rabbit polyclonal antibody to mouse caspase-1 (Servicebio, Wuhan, China), or 1:1000 mouse polyclonal antibody to mouse IL-1 $\beta$ (Servicebio, Wuhan, China), or 1:1000 mouse polyclonal antibody to mouse IL-18 (Servicebio, Wuhan, China) or 1:1000 rabbit polyclonal antibody to mouse $\beta$-actin (Servicebio, Wuhan, China), then 1:5000 goat anti-rabbit IgG (Jackson ImmunoResearch, America) or 1:10,000 goat anti-mouse IgG (Jackson ImmunoResearch, America) as secondary antibodies were used to incubate membranes at room temperature for 1 hour. Bands were detected using ECL plus western blotting detection system, and the intensity was quantified by Image $\mathrm{J}$ software.

\section{Statistical analysis}

Chi-square test was used to compare the tumor incidence among different groups. The results of mean tumor count, lung coefficient and pathological tumor nests were presented as mean $\pm S E M$, and the data analysis was performed by one-way ANOVAs and two-tailed Student's t-test using SPSS21.0 (IBM, NC, USA). The $P$ value less than 0.05 for two-tailed was considered statistically significant.

\section{Results}

\section{Effects of glyburide on fasting blood glucose and body weight alteration in mice}

To investigate the effects of glyburide on FBG and body weight alteration in C57BL/6 mice which were administered $0.48 \mathrm{mg} / \mathrm{kg}$ and $0.96 \mathrm{mg} / \mathrm{kg}$ glyburide by gavage three times a week, the mice treated with glyburide were fasted overnight, and then the FBG and body weight were measured the next morning about once a month. 
Figure 2A and Fig. 2B indicated that chronic glyburide treatment significantly decreased FBG level in both dose at the end of the experiments $(P<0.05)$. Moreover, the FBG of mice treated with Gly $(0.96 \mathrm{mg} / \mathrm{kg})$ significantly decreased more earlier than the mice treated with Gly $(0.48 \mathrm{mg} / \mathrm{kg})$ compared with baseline of FBG level respectively. Figure $2 \mathrm{C}$ shows the body weight of all groups treated with Gly and $\mathrm{B}(\mathrm{a}) \mathrm{P}+\mathrm{LPS}$ group decreased significantly compared with Vehicle group $(P<0.05)$. Also, the mice in B(a)P/LPS + Gly $(0.96 \mathrm{mg} / \mathrm{kg})$ group obviously decreased compared with $\mathrm{B}(\mathrm{a}) \mathrm{P}+\mathrm{LPS}$ and B(a)P/LPS + Gly $(0.48 \mathrm{mg} / \mathrm{kg})$ group $(P<0.05)$.

\section{Glyburide treatment attenuates lung tumorigenesis induced by $B(a) p$ plus LPS in mice}

In order to determine if glyburide inhibits lung tumorigenesis, we compared the incidence and mean tumor count of lung tumors in mice treated with B(a)p plus LPS or B(a)P/LPS + Gly in three sets of tumor bioassays. Figure $3 A$ shows that mice exposed to B(a)p plus LPS could induce lung tumors, whereas there were still no visible lung tumors in Vehicle control group, Gly $(0.48 \mathrm{mg} / \mathrm{kg})$-treated tricaprylin group or Gly $(0.96 \mathrm{mg} / \mathrm{kg})$-treated tricaprylin group. Moreover, treatment with chronic glyburide could inhibit the occurrence of lung tumors induced by B(a)p + LPS in mice. Tumor incidence of mice in B(a)P/LPS + Gly $(0.48 \mathrm{mg} / \mathrm{kg})$ group $(82.6 \%)$ and B(a)P/LPS + Gly $(0.96 \mathrm{mg} / \mathrm{kg})$ group $(70.8 \%)$ were decreased compared with mice exposure to B(a)p plus LPS (89.4\%), but there were no significant difference among these groups (Fig. 3B). In addition, the mice in B(a)P/LPS + Gly $(0.48 \mathrm{mg} / \mathrm{kg})$ group and B(a)P/LPS + Gly $(0.96 \mathrm{mg} / \mathrm{kg})$ group developed $3.22 \pm 3.029,2.13 \pm 2.071$ visible tumors/mouse on the surface of the lung respectively which decreased significantly compared with mice treated with $B(a) p$ plus LPS (5.58 \pm 4.538 tumors/mouse) $(P<0.05)$ (Fig. 3C).

\section{Effect of glyburide on lung coefficient of mice induced by B(a)p plus LPS}

Lung coefficient can reflect lung injury in mice. As shown in the Fig. 3D, mice exposed to B(a)p plus LPS caused the rise of lung coefficient compared with that mice treated with Vehicles $(P<0.05)$. However, chronic glyburide treatment decreased this parameter in the mice of $B(a) p$ plus LPS group that were treated with glyburide. Lung coefficient in mice exposed to B(a)P/LPS + Gly $(0.96 \mathrm{mg} / \mathrm{kg})$ was significantly decreased than mice exposed to B(a)p plus LPS $(P<0.05)$, but there was no significant difference between $\mathrm{B}(\mathrm{a}) \mathrm{P} / \mathrm{LPS}+\mathrm{Gly}(0.48 \mathrm{mg} / \mathrm{kg})$ group and $\mathrm{B}(\mathrm{a}) \mathrm{p}$ plus LPS group. Besides, compared with the Vehicle control group, lung coefficient of mice induced by tricaprylin plus glyburide were both increased, whereas there was no significant difference among these groups.

\section{Effects of glyburide on pathological alterations in the lungs of mice induced by B(a)p plus LPS}

As shown in Fig. 4A, there was no pathological tumor nest in cross-section of the left lobes of lungs in Vehicle control group and Gly-treated tricaprylin group, whereas we could observe pathological tumor nest in both $\mathrm{B}(\mathrm{a}) \mathrm{P} / \mathrm{LPS}+\mathrm{Gly}(0.48 \mathrm{mg} / \mathrm{kg})(0.38 \pm 0.18)$ and $\mathrm{B}(\mathrm{a}) \mathrm{P} / \mathrm{LPS}+\mathrm{Gly}(0.96 \mathrm{mg} / \mathrm{kg})(1.31 \pm 0.35)$ group significantly decreased compared with $\mathrm{B}(\mathrm{a}) \mathrm{p}$ plus LPS group $(3.56 \pm 1.02)(P<0.05)$ (Fig. 4B). Meanwhile, we found the significantly inflammatory changes in mice exposed to $B(a) p$ plus LPS including infiltration of inflammatory cells, fractures of alveolar walls and injury of bronchial epithelium 
compared with Vehicles group(Fig. 4C). However, chronic glyburide treatment could reduce the inflammatory changes significantly in mice induced by $B(a) p$ plus LPS.

\section{The expression of NLRP3, IL-1 $\beta$ and IL-18 protein in lung tissues of mice in different groups}

The expression of NLRP3, IL-1 $\beta$ and IL-18 protein in lung tissues was observed by using immunohistochemistry. Figure 5A shows that positive expression areas of NLRP3, IL-1 $\beta$ and IL-18 were in the cytoplasm. As shown in the Fig. 5B, the expression of NLRP3 and IL-1 $\beta$ protein in lung tissues of mice exposure to $\mathrm{B}(\mathrm{a}) \mathrm{p}$ plus LPS were higher than those in Vehicle control group $(P<0.05$, respectively), however, the levels of NLRP3 and IL-1 $\beta$ protein in lung tissues of B(a)P/LPS + Gly0.96 (mg/kg)-treated mice were significant decreased compared with those in $\mathrm{B}(\mathrm{a}) \mathrm{p}$ plus LPS group $(P<0.05$, respectively). Moreover, there was no significant difference on the level of IL-18 protein in lung tissues of B(a)P/LPS + Gly0.48/0.96 (mg/kg) compared with that in B(a)p plus LPS group (Fig. 5B). Above results indicated that the downregulation of the expression of NLRP3 and IL-1 $\beta$ protein could due to the chronic treatment in lung tissues of mice.

\section{The expression of Cleaved-IL-1 $\beta$ protein in lung tissues of mice in different groups}

As shown in Fig. 6 , the level of Cleaved-IL-1 $\beta$ protein were increased induced by $B(a) p$ plus LPS in lung tissues of mice compared with that in Vehicle control group $(P<0.05)$, but the level of Cleaved-IL-1 $\beta$ protein in $\mathrm{B}(\mathrm{a}) \mathrm{P} / \mathrm{LPS}+\mathrm{Gly} 0.96(\mathrm{mg} / \mathrm{kg})$ group decreased significantly than that in $\mathrm{B}(\mathrm{a}) \mathrm{p}$ plus LPS group $(P<0.05)$.

\section{Discussion}

There has been increasing evidence showing that glyburide is involved in the progression of cancer. However, glyburide has been studied mainly according to its pharmacological effects on the potassium channels but only a little part of its antitumor effects has been paid attention to in nondiabetic models of this drug systematically, also, the evidence of its effect in the lung tumorigenesis remains unclear. Thus, we explored the role of glyburide in lung tumorigenesis which could contribute to a new therapeutic strategy for lung cancer using the non-diabetes mice model induced by B(a)p plus LPS.

Chronic glyburide treatment decreased the FBG significantly, and mice exposed to B(a)p plus LPS significantly decreased weight compared with mice in Vehicle control group which may be attributed to the cancer cachexia[28]. Glyburide is one of the most common medication used in the treatment of type 2 diabetes, however, the FBG of the mice significantly decreased during chronic glyburide treatment, this would be a side effect of glyburide treatment.

Previous studies show that glyburide could have antiproliferative effects on cancer cell growth in some cancer models, but its role was inconsistent with some clinical studies. Findings from preclinical studies demonstrated it could inhibit growth of human prostate[29], hepatocellular[22], breast[30], gastric[31], bladder[32], glioma[33] and colon[20] cancer cell lines in vitro. Furthermore, for in vivo experiments, one 
article indicated the impact of glyburide in combination with cobalt chloride $(\mathrm{CoCl} 2)$ on the growth and invasiveness of Tientsin Albino 2 (TA2) breast cancer, and the expression of metal matrix proteinase- 9 (MMP-9) and proliferating cell nuclear antigen (PCNA) could be decreased by the treatment, due to MMP9 being involved in the cancer invasion and metastasis, while PCNA participation in nucleic acid metabolism and DNA synthesis as an accessory protein, Zhe Rong et al found this combined treatment inhibited TA2 spontaneous breast cancer growth and invasiveness[34]. Another study for non-diabetes rat models induced with $N$-Nitroso- $N$-Methylurea, in the presence of glyburide, breast cancer cell growth could also be inhibited[24]. One clinical study indicated an association between glyburide and higher cancer risk[13] and a retrospective study with a mean follow-up of 5 years, showed a higher all-cancer mortality in glyburide users compared to gliclazide users[12]. In our study, we found that glyburide could attenuate lung tumorigenesis, chronic glyburide treatment decreased tumor incidence and mean tumor count of visible tumors on the surface of lungs. In addition, the increase of lung coefficient is related with lung injury in mice, and B(a)p plus LPS exposure increased lung coefficient significantly. We found that chronic treatment glyburide significantly decreased lung coefficient compared with mice exposed to $B(a) p$ plus LPS, and the reduced lung coefficient may be attributed to the number of tumor nodules decreased. All these evidences demonstrated that glyburide could induce the inhibition of occurrence of lung tumors in nondiabetic mice which was in line with the above reports about the anti-tumor effect of glyburide.

Histopathological observation confirmed that the number of pathological tumor nest of the left lobes of lungs decreased significantly after glyburide treatment compared with the mice in B(a)p plus LPS group and lung inflammatory changes were relieved. As evidence indicated that glyburide could induce inhibition of occurrence of lung tumor through inhibiting the inflammation. It has been reported that all stages of tumorigenesis could be affected by inflammation[35], and the anti-inflammatory effects of glyburide have been indicated[36, 37]. It is surprising that the number of pathological tumor nest in group of $B(a) P / L P S+G l y(0.48 \mathrm{mg} / \mathrm{kg})$ decreased compared with the mice in $B(a) P / L P S+G l y(0.96 \mathrm{mg} / \mathrm{kg})$ group. One reasonable explanation for this result is that we counted the number of pathological tumor nest only in the left lobes of lungs but not the whole lung tissues in mice.

Moreover, immunohistochemical results demonstrated that the expression of NLRP3 and IL-1 $\beta$ protein were higher in $\mathrm{B}(\mathrm{a}) \mathrm{P}+\mathrm{LPS}$ group than those in Vehicle control group, which were in accordance with our previous study. Comparing with $\mathrm{B}(\mathrm{a}) \mathrm{P}+\mathrm{LPS}$ group, the expression of NLRP3 and IL-1 $\beta$ protein both decreased after chronic glyburide treatment. IL-1 $\beta$ plays an important role in the downstream of NLRP3 inflammasome served as a proinflammatory cytokine, and it also could promote the progression in lung tumor[38]. Glyburide has anti-inflammatory response mainly by inhibiting the activation of NLRP3 inflammasome and decreasing IL-1 $\beta$ release[39]. Thus, we next examined the levels of cleaved-IL-1 $\beta$ protein in Gly $(0.96 \mathrm{mg} / \mathrm{kg})$-treated group decreased significantly compared with $\mathrm{B}(\mathrm{a}) \mathrm{P}+\mathrm{LPS}$ group.

Taken together, glyburide could inhibit the expression of cleaved-IL-1 $\beta$ in lung tumorigenesis induced by $\mathrm{B}(\mathrm{a}) \mathrm{P}$ plus LPS, which may be attributed to attenuate inflammation-related lung tumorigenesis in mice. It has been reported that in an ex vivo model of human endotoxinemia, glyburide could reduce proinflammatory cytokines including LPS-induced releases of IL-1 $\beta$ and tumor necrosis factor $a$ (TNF-a) [40], besides, the proliferation and migration of lung adenocarcinoma cell line A549 could be enhanced by 
the upregulation of IL-1 $\beta$ which were induced by the activation of NLRP3 inflammasome[38, 41].

Therefore, it suggests that glyburide might inhibit NLRP3 inflammasome to attenuate the inflammationrelated lung cancer induced by $B(a) p$ plus LPS.

\section{Conclusion}

In conclusion, our results demonstrated that chronic glyburide treatment attenuated inflammation-related lung tumorigenesis in non-diabetes mice which might by inhibiting NLRP3 inflammasome in this study. However, we need to further explore the mechanism of glyburide alleviated lung tumorigenesis.

\section{Abbreviations}

Gly glyburide

$B(a) p$ benzo(a)pyrene

LPS lipopolysaccharide

FBG fast blood glucose

HE haematoxylin and eosin

IHC immunohistochemistry

PVDF Polyvinylidene Fluoride

$\mathrm{CoCl} 2$ cobalt chloride

TA2 Tientsin Albino 2

MMP-9 metal matrix proteinase-9

PCNA proliferating cell nuclear antigen

TNF-a tumor necrosis factor a

\section{Declarations}

Ethics approval and consent to participate

All studies were approved by the life Science Institutional Review Board of Zhengzhou University and performed strictly in accordance with the Guideline of Zhengzhou University for Animal Experiments

\section{Consent for publication}


Not applicable.

\section{Availability of data and materials}

The data that support the findings of this study are available on request from the corresponding author. The data are not publicly available due to them containing information that could compromise research participant privacy/consent.

\section{Competing interests}

The authors declare that they have no competing financial interests.

\section{Funding}

This study was supported by the National Natural Science Foundation of China (No. 81402712); the training grant of Zhengzhou University (2017ZDGGJS039); the grant from the Department of Education of Henan Province, China (No.20B330004 and 20B320042); and the grant of Medical Science Research Foundation of Henan Province (No. 2018020477 and SB201901016).

\section{Authors' contributions}

All authors have contributed significantly. All authors read and approved the final manuscript.

\section{Acknowledgements}

Not applicable.

\section{References}

1. Cai Z, Liu Q. Understanding the Global Cancer Statistics 2018: implications for cancer control. Sci China Life Sci. 2019;1-4.

2. SiegelRL MillerKD, Cancer statistics JemalA. 2020. CA A Cancer J Clin. 2020;70: 7-30.

3. Singh Z, Chadha P. Textile industry and occupational cancer. J Occup Med Toxicol. 2016;11(1).

4. Petit P, Maitre A, Persoons R, Bicout DJ. Lung cancer risk assessment for workers exposed to polycyclic aromatic hydrocarbons in various industries. Environ Int. 2019;124:109-20.

5. Moossavi M, Parsamanesh N, Bahrami A, Atkin SL, Sahebkar A. Role of the NLRP3 inflammasome in cancer. Mol Cancer. 2018;17:13.

6. Lee C, Do HTT, Her J, Kim Y, Seo D, Rhee I. Inflammasome as a promising therapeutic target for cancer. Life Sci. 2019;231:8.

7. Huang L, Duan S, Shao H, Zhang A, Chen S, Zhang P, et al. NLRP3 deletion inhibits inflammationdriven mouse lung tumorigenesis induced by benzo(a)pyrene and lipopolysaccharide. Resp Res. 2019;20(1). 
8. Gao M, Zhang P, Huang L, Shao H, Duan S, Li C, et al. Is NLRP3 or NLRP6 inflammasome activation associated with inflammation-related lung tumorigenesis induced by benzo(a)pyrene and lipopolysaccharide?Ecotox Environ Safe. 2019;185.

9. Carvalho AM, Novais FO, Paixao CS, de Oliveira Cl, Lima Machado PR, Carvalho LP, et al. Glyburide, a NLRP3 Inhibitor, Decreases Inflammatory Response and Is a Candidate to Reduce Pathology in Leishmania braziliensis Infection. J Invest Dermatol. 2020;140:246-+.

10. Gao R, Yang T, Xu W. Enemies or weapons in hands: investigational anti-diabetic drug glibenclamide and cancer risk. Expert Opin Inv Drug. 2017:1-12.

11. Bo S, Castiglione A, Ghigo E, Gentile L, Durazzo M, Cavallo-Perin P, et al. Mortality outcomes of different sulphonylurea drugs: the results of a 14-year cohort study of type 2 diabetic patients. Eur $\mathrm{J}$ Endocrinol. 2013;169:117-26.

12. Monami M, Balzi D, Lamanna C, Barchielli A, Masotti G, Buiatti E, et al. Are sulphonylureas all the same? A cohort study on cardiovascular and cancer-related mortality. Diabetes-metab Res. 2010;23:479-84.

13. Monami M, Lamanna C, Balzi D, Marchionni N, Mannucci E. Sulphonylureas and cancer: A casecontrol study. Acta Diabetol. 2008;46:279-84.

14. Marco T, Jennifer, Wu, Hui Y, et al. The Use of Glyburide Compared With Other Sulfonylureas and the Risk of Cancer in Patients With Type 2 Diabetes. Diabetes Care. 2015;38(11):2083-9.

15. Yang X, So WY, Ma RCW, Yu LWY, Ko GTC, Kong APS, et al. Use of sulphonylurea and cancer in type 2 diabetes-The Hong Kong Diabetes Registry. Diabetes ResClin Pr. 2010;90(3):343-51.

16. Jian Gang P, Mo L, Lu Y, Runqi L, Xing Z. Diabetes mellitus and the risk of prostate cancer: an update and cumulative meta-analysis. Endocr Res Commun. 2015;40:54-61.

17. Konstantinos K, Tsilidis NEA, Paul N, Appleby,Sabine Rohrmann,Ute Nöthlings,Larraitz Arriola,Marc JG, Veronique, Chajes, et al. Diabetes mellitus and risk of prostate cancer in the European Prospective Investigation into Cancer and Nutrition.Int J Cancer. 2015;136(2):372-381.

18. Wondergem R, Cregan M, Strickler L, Miller R, Suttles J. Membrane Potassium Channels and Human Bladder Tumor Cells: II. Growth Properties. J Membr Biol. 1998;161:257-62.

19. Abdul M, Hoosein N. Expression and activity of potassium ion channels in human prostate cancer. Cancer Lett. 2002;186:0-105.

20. Abdul H. Voltage-gated potassium ion channels in colon cancer. Oncol Rep. 2002;9:961-4.

21. Malhi H, Irani AN, Rajvanshi P, Suadicani SO, Spray DC, McDonald TV, et al. KATP channels regulate mitogenically induced proliferation in primary rat hepatocytes and human liver cell lines. Implications for liver growth control and potential therapeutic targeting. $\mathrm{J}$ biol chem. 2000;275:26050-7.

22. Zhou Q, Kwan HY, Chan HSC, Jiang JL, Tam SC, Yao XQ. Blockage of voltage-gated K+ channels inhibits adhesion and proliferation of hepatocarcinoma cells. Int J Mol Med. 2003;11:261-6. 
23. da Silva Franco CC, Previate C, de Barros Machado KG, Piovan S, Miranda RA, Prates KV, et al. Chronic Glibenclamide Treatment Attenuates Walker-256 Tumour Growth in Prediabetic Obese Rats. Cell Physiol Biochem. 2017;42:81-90.

24. Cocca C, Martin G, Nunez M, Gutierrez A, Cricco G, Mohamad N, et al. Effect of glibenclamide on Nnitroso-N-methylurea-induced mammary tumors in diabetic and nondiabetic rats. Oncol Res. 2005;15:301-11.

25. Huang L, Duan S, Shao H, Zhang A, Chen S, Zhang P, et al. NLRP3 deletion inhibits inflammationdriven mouse lung tumorigenesis induced by benzo(a)pyrene and lipopolysaccharide. Respir Res. 2019;20:20.

26. Qian X, Melkamu T, Upadhyaya P, Kassie F. Indole-3-carbinol inhibited tobacco smoke carcinogeninduced lung adenocarcinoma in $\mathrm{A} / \mathrm{J}$ mice when administered during the post-initiation or progression phase of lung tumorigenesis. Cancer Lett. 2011;311:57-65.

27. Dagne A, Melkamu T, Schutten MM, Qian X, Upadhyaya P, Luo X, et al. Enhanced inhibition of lung adenocarcinoma by combinatorial treatment with indole-3-carbinol and silibinin in A/J mice. Carcinogenesis. 2011;32:561-7.

28. Torricelli P, Antonelli F, Ferorelli P, Borromeo I, Shevchenko A, Lenzi S, et al. Oral nutritional supplement prevents weight loss and reduces side effects in patients in advanced lung cancer chemotherapy. Amino Acids. 2020;52:445-51.

29. Abdul M, Hoosein N. Expression and activity of potassium ion channels in human prostate cancer. Cancer Lett. 2002;186:99-105.

30. Nunez M, Medina V, Cricco G, Croci M, Cocca C, Rivera E, et al. Glibenclamide inhibits cell growth by inducing G0/G1 arrest in the human breast cancer cell line MDA-MB-231. Bmc Pharmacol Toxico. 2013;14.

31. Qian X, Li J, Ding J, Wang Z, Duan L, Hu G. Glibenclamide exerts an antitumor activity through reactive oxygen species-c-jun $\mathrm{NH}(2)$-terminal kinase pathway in human gastric cancer cell tine MGC803. Biochem Pharmacol. 2008;76:1705-15.

32. Wondergem R, Cregan M, Strickler L, Miller R, Suttles J. Membrane potassium channels and human bladder tumor cells: II. Growth properties. J membrane biol. 1998;161:257-62.

33. Li Chao-Ying. Voltage-gated and ATP-sensitive $\mathrm{K}+$ channels are associated with cell proliferation and tumorigenesis of human glioma. Oncol Rep. 2013.

34. Rong Z, Li L, Fei F, Luo L, Qu Y. Combined treatment of glibenclamide and $\mathrm{CoCl} 2$ decreases MMP9 expression and inhibits growth in highly metastatic breast cancer. J Exp Clin Canc Res. 2013;32.

35. Wang Z, Wang N, Zheng Y, Wang S. Inflammasome Cancer Experientia suppl. 2018;108:281-302.

36. Koh GCKW, Maude RR, Schreiber MF, Limmathurotsakul D, Wiersinga WJ, Wuthiekanun V, et al. Glyburide Is Anti-inflammatory and Associated with Reduced Mortality in Melioidosis. Clin Infect Dis. 2011;52:717-25.

37. Simard JM, Geng Z, Woo SK, Ivanova S, Tosun C, Melnichenko L, et al. Glibenclamide reduces inflammation, vasogenic edema, and caspase-3 activation after subarachnoid hemorrhage. J Cerebr 
Blood F Met. 2009;29:872-2.

38. Terlizzi M, Colarusso C, Popolo A, Pinto A, Sorrentino R. IL-1 alpha and IL-1 beta-producing macrophages populate lung tumor lesions in mice. Oncotarget. 2016;7:58181-92.

39. Lowes DJ, Hevener KE, Peters BM. Second-Generation Antidiabetic Sulfonylureas Inhibit Candida albicans and Candidalysin-Mediated Activation of the NLRP3 Inflammasome. Antimicrob Agents Ch. 2020;64.

40. Schmid D, Svoboda M, Sorgner A, Moravcevic I, Thalhammer T, Chiba P, et al. Glibenclamide reduces proinflammatory cytokines in an ex vivo model of human endotoxinaemia under hypoxaemic conditions. Life Sci. 2011;89:725-34.

41. Wang Y, Kong H, Zeng X, Liu W, Wang Z, Yan X, et al. Activation of NLRP3 inflammasome enhances the proliferation and migration of A549 lung cancer cells. Oncol Rep. 2016;35:2053-64.

\section{Figures}

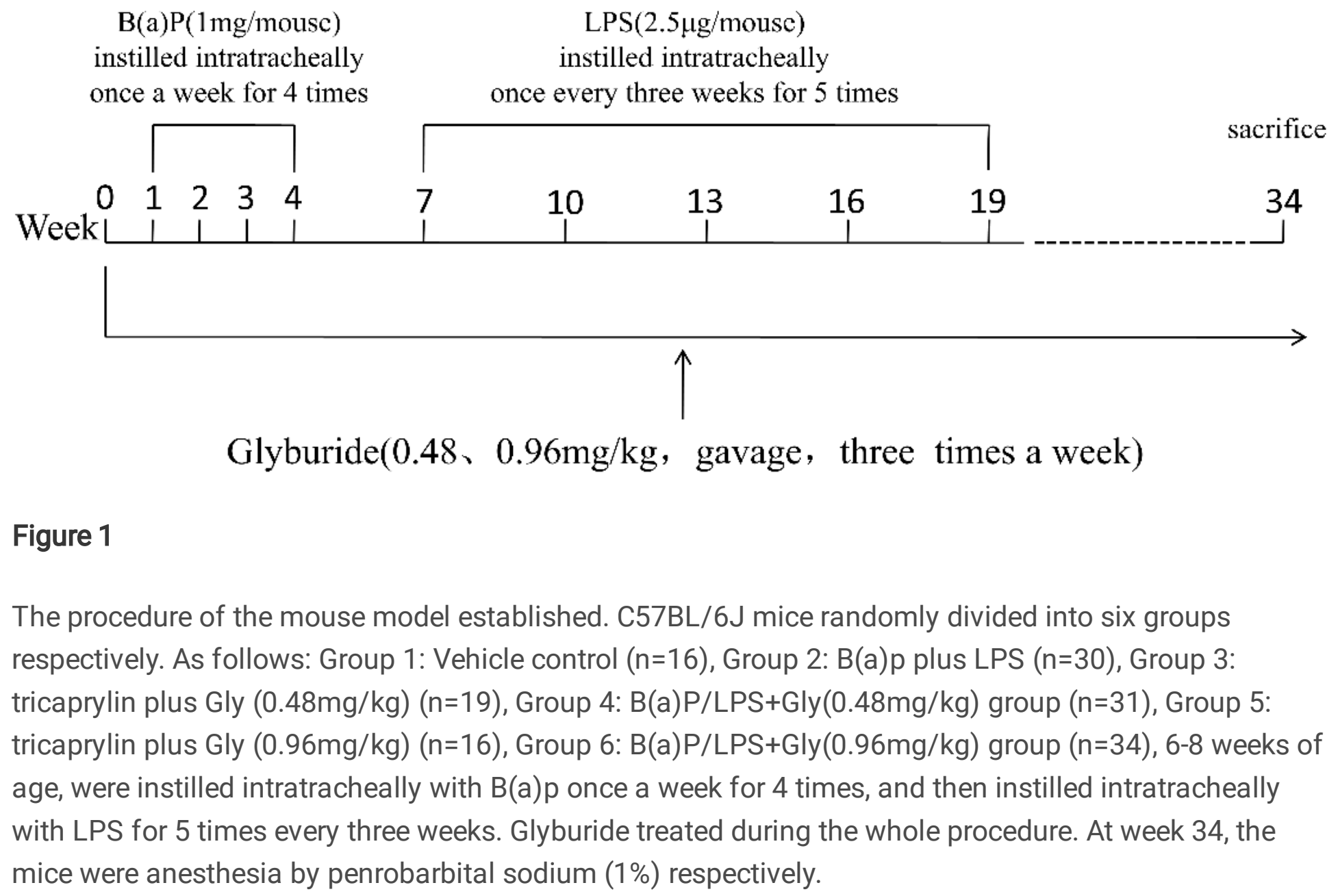



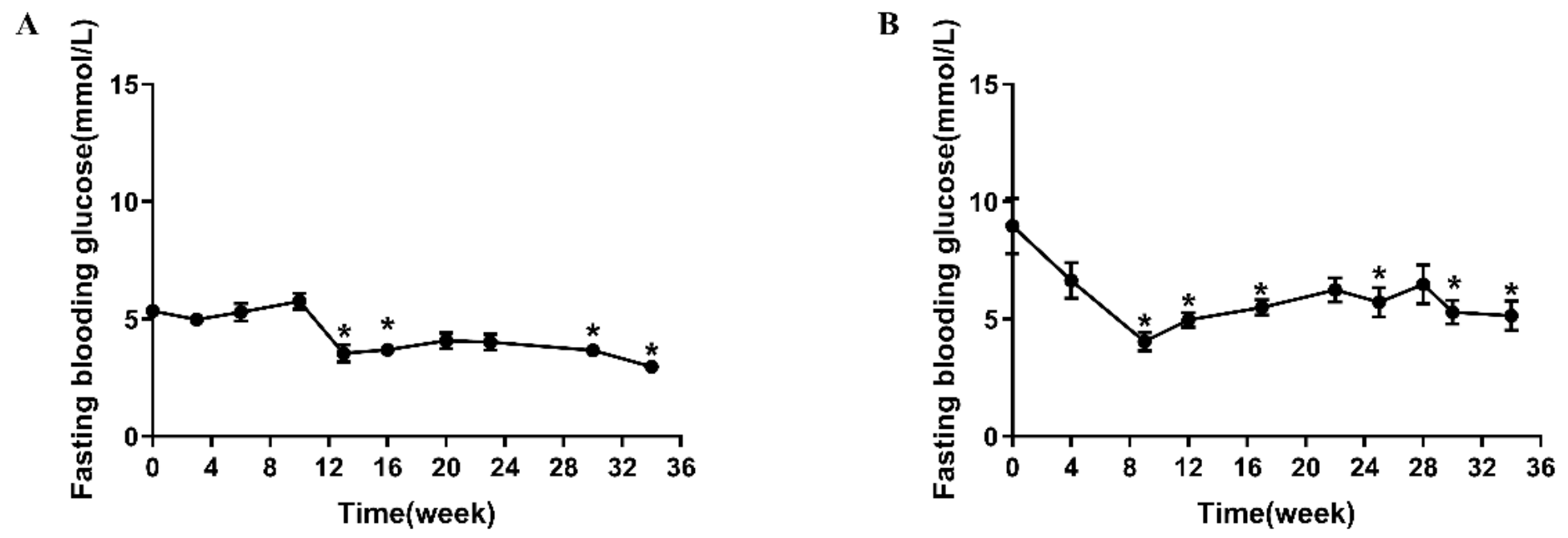

C

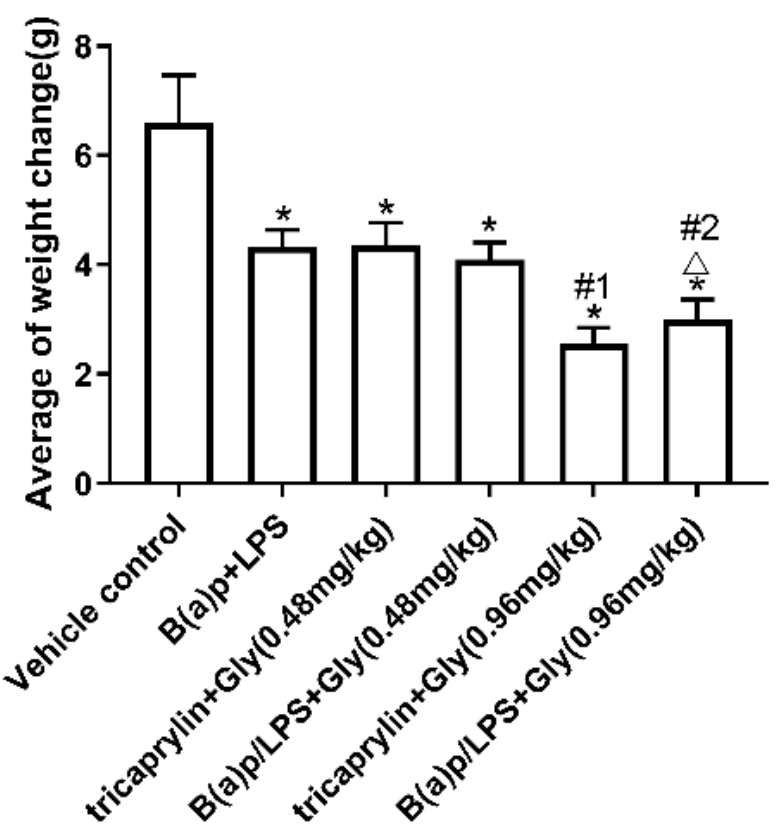

Figure 2

Fast blood glucose alterations and body weight alterations after the mice treated with glyburide.

Detection of fast blood glucose about once a month, which the values were presented as mean \pm SEM.

Fast blood glucose alterations: mice treated with Gly $(0.48 \mathrm{mg} / \mathrm{kg})(A)$, mice treated with Gly $(0.96 \mathrm{mg} / \mathrm{kg})$

(B). Body weight alterations (C) *: vs baseline of fast blood glucose. *: vs Vehicle control, $\Delta$ : vs B(a)P+LPS, \#1: vs Tricaprylin+Gly(0.48mg/kg), \#2: vs B(a)P/LPS+Gly $(0.48 \mathrm{mg} / \mathrm{kg}), P<0.05$. 


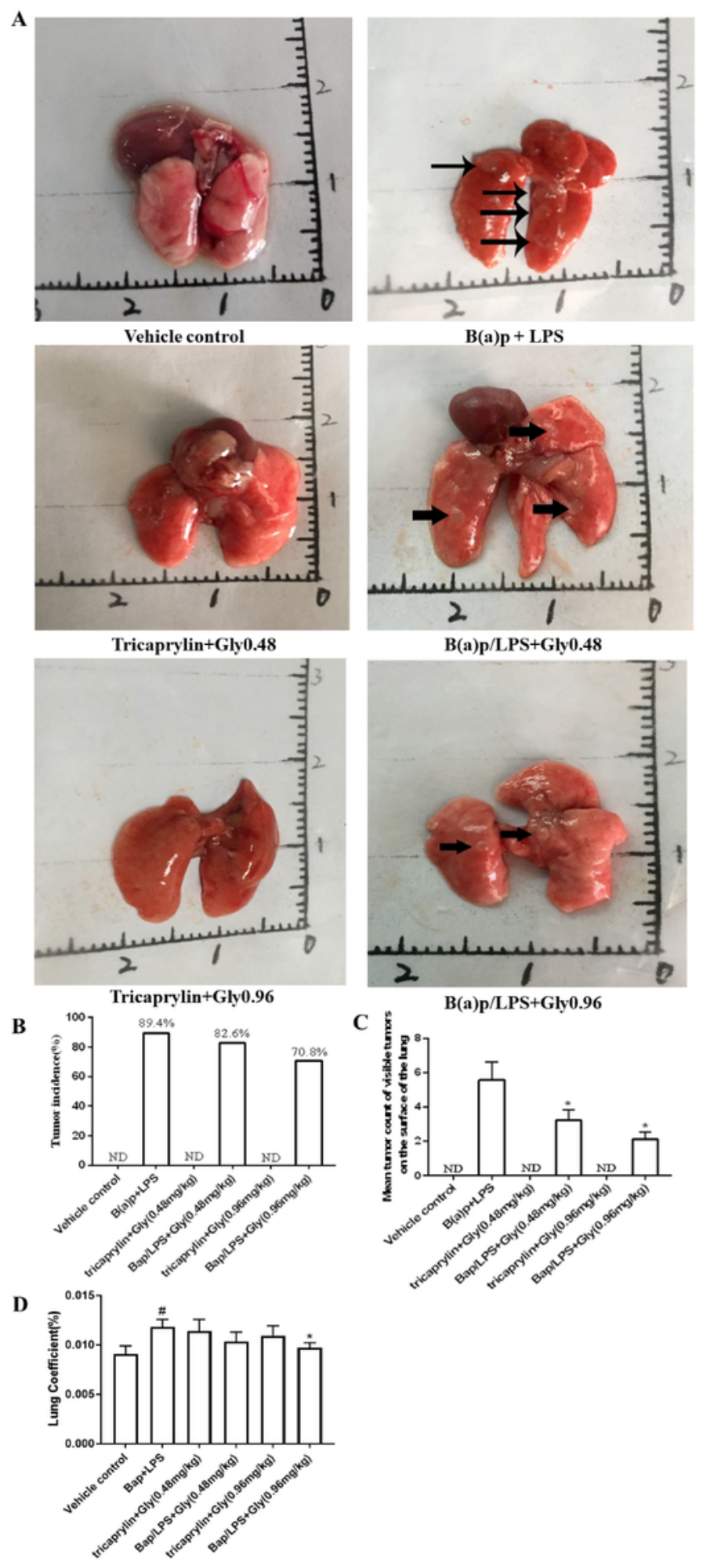

\section{Figure 3}

Chronic glyburide treatment alleviated lung tumorigenesis induced by $\mathrm{B}(\mathrm{a}) \mathrm{p}$ plus LPS. The alterations in lungs of mice exposed to Vehicle control, B(a)p plus LPS, tricaprylin+Gly0.48 $(\mathrm{mg} / \mathrm{kg})$, B(a)P/LPS+Gly0.48 (mg/kg), tricaprylin+Gly0.96 (mg/kg), B(a)P/LPS+Gly0.96 (mg/kg) (A). The tumor incidence (B), mean tumor count (C) of visible tumors on the surface of the lung in mice.Lung coefficient of mice (D) exposed to Vehicle control, B(a)p plus LPS, Gly $(0.48 \mathrm{mg} / \mathrm{kg})$-treated tricaprylin, B(a)P/LPS+Gly 
(0.48mg/kg), Gly $(0.96 \mathrm{mg} / \mathrm{kg})$-treated tricaprylin, B(a)P/LPS+Gly $(0.96 \mathrm{mg} / \mathrm{kg})$.Black arrows show visible tumors on the surface of the lung. *: vs $B(a) p$ plus LPS, $P<0.05$; \#: vs Vehicle control, $P<0.05$. ND: Not Detectable.
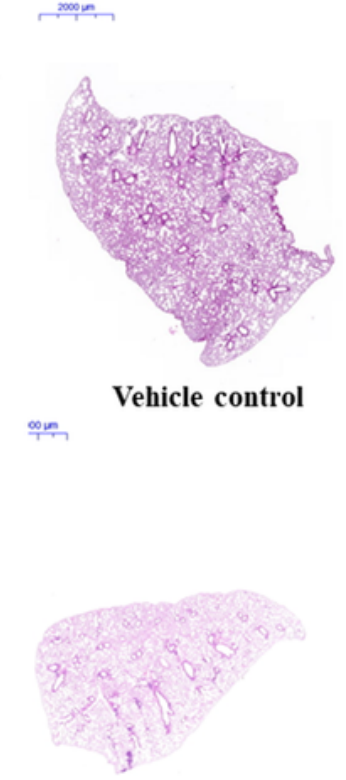

Tricaprylin+Gly0.48

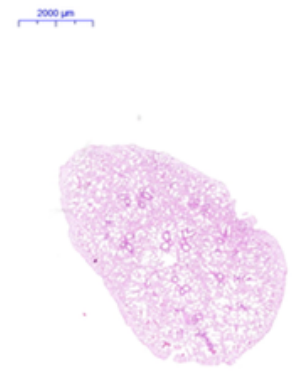

Tricaprylin+Gly0.96

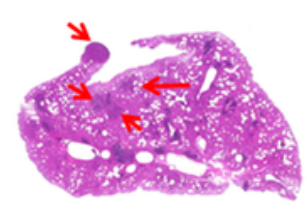

B(a)p+LPS

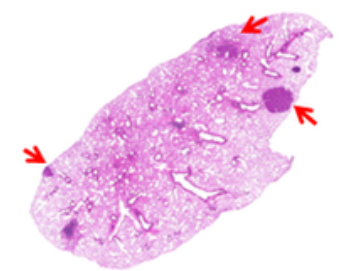

B(a)p/LPS+Gly0.48

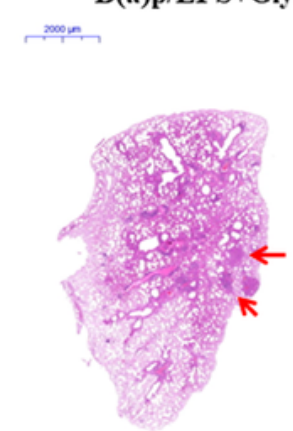

B(a)p/LPS+Gly0.96
$\mathrm{C}$
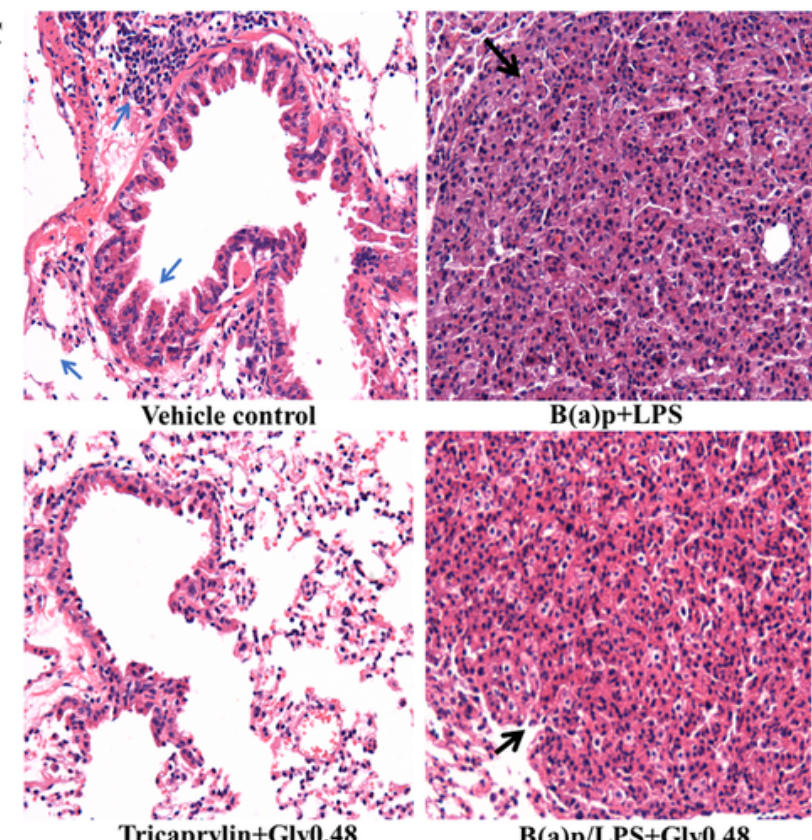

B(a)p+LPS

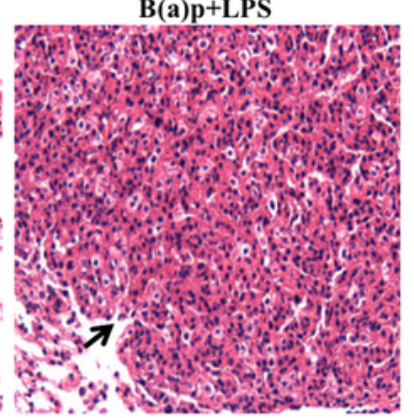

B(a)p/LPS+Gly0.48

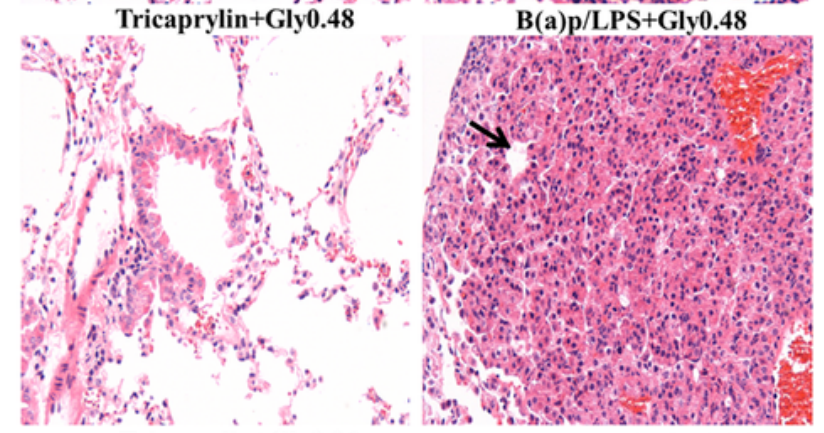

Tricaprylin+Gly0.96

B(a)p/LPS+Gly0.96

B

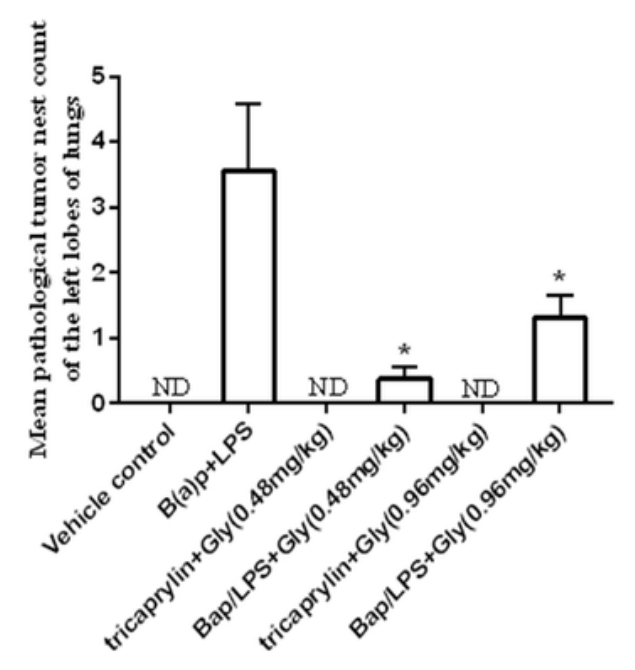

Figure 4

Pathological alterations in the cross-section of the left lobes of lungs in mice The pulmonary morphological alterations in the left lobes of lungs of mice exposed to Vehicle control, B(a)p plus LPS, 
tricaprylin+Gly0.48 (mg/kg), B(a)P/LPS+Gly0.48 (mg/kg), tricaprylin+Gly0.96 (mg/kg), $\mathrm{B}(\mathrm{a}) \mathrm{P} / \mathrm{LPS}+\mathrm{Gly} 0.96(\mathrm{mg} / \mathrm{kg})(\mathrm{A})$. The numbers of pathological tumor nests in cross-section of the left lobes of lungs in above all groups (B). Pulmonary pathological alterations were analyzed by HE staining in mice with amplification (200x)(C). *: vs $B(a) p$ plus LPS $p<0.05$. Red arrows suggest pathological tumor nests in cross-section of the lobes of lungs. ND: Not Detectable. Blue arrows indicate inflammatory changes in mice, including infiltration of inflammatory cells fractures of alveolar walls and injury of bronchial epithelium. Black arrows exhibit pathological tumor nest in mice.

A
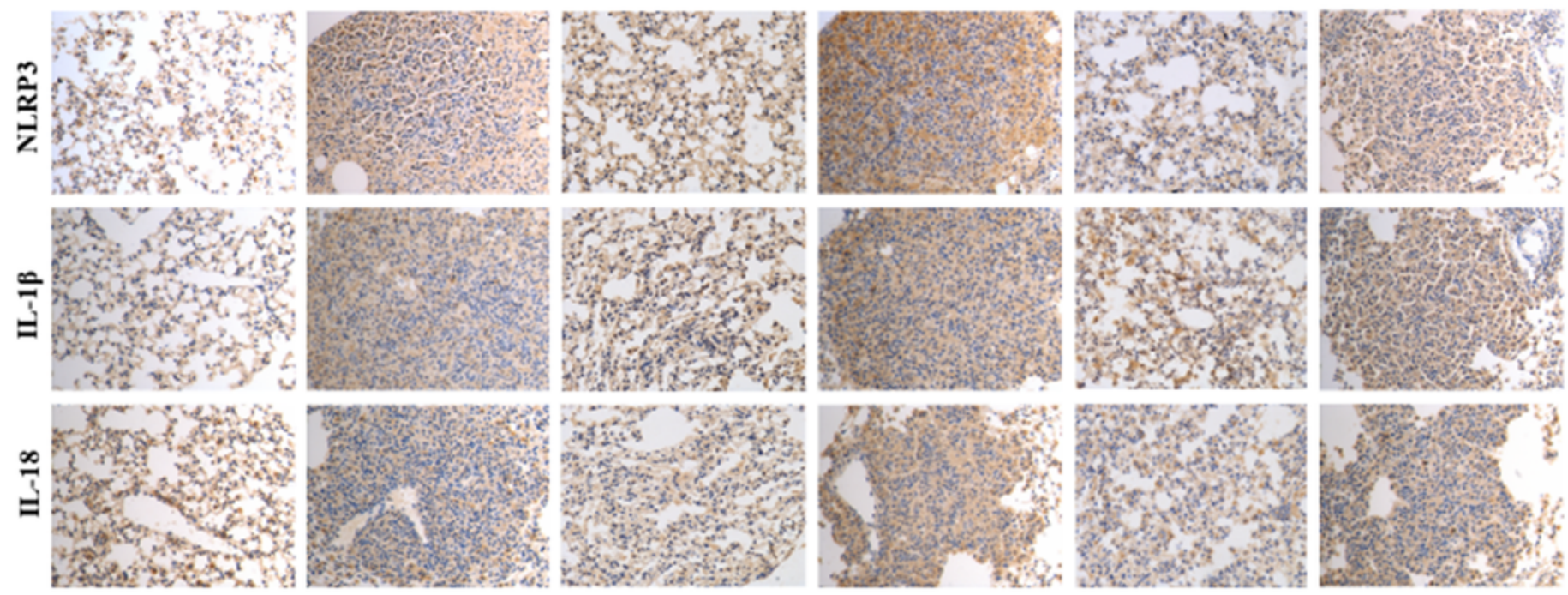

Vehicles control

B(a)p plus LPS

Tricaprylin+Gly0.48 B(a)p/LPS+Gly0.48

Tricaprylin+Gly0.96

B(a)p/LPS+Gly0.96

B

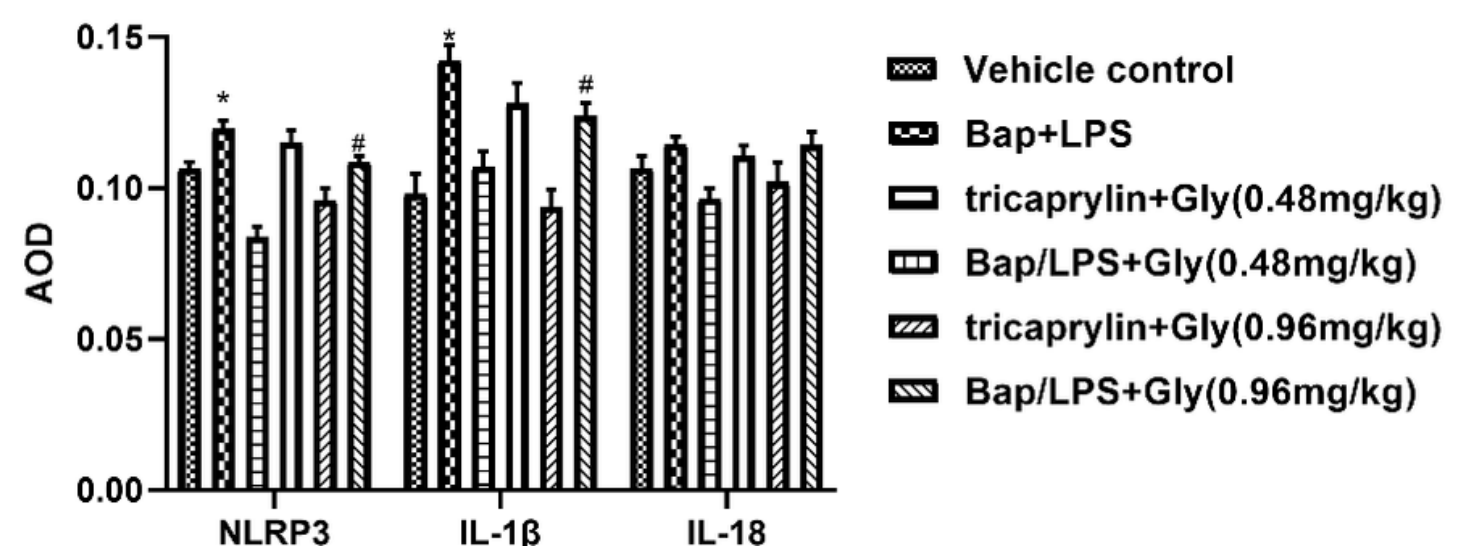

Figure 5

The expression of NLRP3, IL-1 $\beta$ and IL-18 protein in lung tissues in different groups. The representative images of IHC staining of NLRP3, IL-1 $\beta$ and IL-18 protein in lung tissue with amplification (200X) from mice exposed to Vehicle control, B(a)p plus LPS, tricaprylin+Gly0.48 (mg/kg), B(a)P/LPS+Gly0.48 (mg/kg), tricaprylin+Gly0.96 (mg/kg), B(a)P/LPS+Gly0.96 (mg/kg), respectively (A). Levels of NLRP3, IL$1 \beta$ and IL-18 protein were quantified using AOD in 10 high vision field using Image-Pro Plus 6.0 software (B). Data were expressed as mean \pm SEM. *: vs Vehicle control, $P<0.05$; \#: vs $B(a) P+L P S, P<0.05$ 


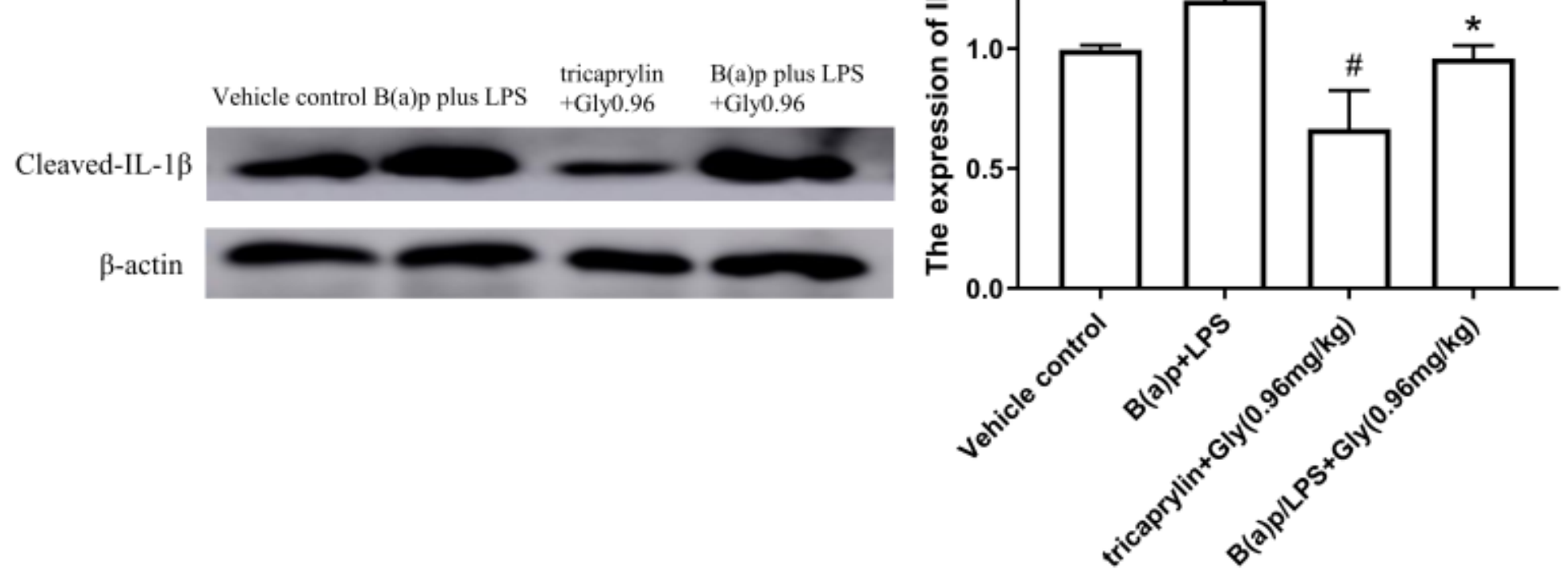

Figure 6

$B(a) p$ plus LPS exposure induced NLRP3 inflammasome activation in lung tissues. The expression of cleaved-IL-1 $\beta$ protein in lung tissues was examined using Western blot $(A)$. The expression of IL-1 $\beta$ (B). Data were expressed as mean \pm SEM. *: vs Vehicle control, $P<0.05$; \#: vs $B(a) P+L P S, P<0.05$. 